\title{
RETRACTION
}

Check for updates

Cite this: J. Mater. Chem. C, 2020 , 8, 2597

DOI: $10.1039 /$ d0tc90027c

rsc.li/materials-c

\section{Retraction: 3D printed highly flexible strain sensor based on TPU-graphene composite for feedback from high speed robotic applications}

\author{
Jahan Zeb Gul, ${ }^{\text {ac }}$ Memoon Sajid ${ }^{\text {bc }}$ and Kyung Hyun Choi*c
}

Retraction of '3D printed highly flexible strain sensor based on TPU-graphene composite for feedback from high speed robotic applications' by Jahan Zeb Gul et al., J. Mater. Chem. C, 2019, 7, 4692-4701.

We, the named authors, wholly retract this Journal of Materials Chemistry $C$ article as we noticed, after publication, many significant and uncanny similarities between the article and a paper published in Carbon. ${ }^{1}$

We, Prof. K. H. Choi and Dr M. Sajid, summarize the similarities as follows:

1. Fig. $4 \mathrm{~d}$ and $\mathrm{e}$ in this paper and Fig. $4 \mathrm{~d}$ and e in ref. 1 are almost identical, including the values.

2. Fig. 5a-c, e and $\mathrm{f}$ in this paper and Fig. 4f, g, Fig. S19, Fig. $4 \mathrm{~h}$ and Fig. S22, respectively, in ref. 1 are also identical.

3. Fig. 6a-e in this paper and Fig. 5a, b, e, Fig. S25 and Fig. S26, respectively, in ref. 1 are almost the same, including the time axes.

4. Fig. 7 in this paper and Fig. S29a, Fig. 6a-i and Fig. 7e in ref. 1 all have a high degree of similarity.

Upon identification, we, Prof. Choi and Dr Sajid, duly notified the journal's editorial team and requested guidance and suitable action. The Royal Society of Chemistry consulted with an independent expert who stated that they did not believe that the data is original because the observed level of reproducibility between this paper and ref. 1 is not possible. In addition to the figure similarity, there is also a high degree of text overlap observed in the Results and discussion and Conclusion sections of the article and the Carbon paper.

In order to protect the integrity and accuracy of the scientific record, the authors voluntarily requested to retract this article.

Signed: Jahan Zeb Gul, Memoon Sajid and Kyung Hyun Choi

Date: 7 th January 2020

Retraction endorsed by Sam Keltie, Executive Editor, Journal of Materials Chemistry C

\section{References}

1 Y. Wang, J. Hao, Z. Huang, G. Zheng, K. Dai, C. Liu and C. Shen, Carbon, 2018, 126, 360-371.

\footnotetext{
${ }^{a}$ Department of Mechatronics Engineering, AIR University, E-9, Islamabad, Pakistan. E-mail: jahanzebgul89@gmail.com

${ }^{b}$ Faculty of Electrical Engineering, Ghulam Ishaq Khan (GIK) Institute, Topi, Pakistan

${ }^{c}$ Jeju National University, Jeju-si, South Korea. E-mail: amm@jejunu.ac.kr
} 